\title{
Occupational health and safety in Great Britain in 1971
}

\author{
W. R. LEE \\ Department of Occupational Health, University of Manchester
}

The two things which struck me when reading the annual reports on health and safety were, first, the influence of the Robens Committee both on the inspectors and on my approach to the reports and, secondly, the improvements in statistical analysis of accidents during the past few years.

\section{General}

The reports show differing acceptance of one of the major conclusions of the Robens Committee, that we should move from the concept of detailed regulation by external agencies to a system of selfinspection and self-regulation. The chief inspector of factories aims to use his limited resources selectively and effectively. His inspectors will seek a more penetrating inspection than hitherto, sometimes obtaining the management's co-operation before the visit and perhaps alerting the appropriate trade unions. Contrast this with the report on the Office, Shop and Railway Premises Act that 'authorities were generally agreed that regular routine inspections were essential to keep premises up to the mark' and 'regular inspection is undoubtedly the finest way of enforcing the act'. It is interesting to reflect that both of these reports came from the Department of Employment.

There will clearly be some need for co-ordination of views when another of the Robens Committee proposals is implemented, the amalgamation of all the inspectorates into a unified authority. The overlap of interests is apparent from time to time, although I was a little surprised how infrequently. The alkali inspector tells of an incident when a pipeline carrying hydrogen sulphide broke and some employees were adversely affected but later recovered. The factory inspector tells of only one person gassed by hydrogen sulphide.

\section{Inspectorates and the community}

However, it is in new problems from the very large size of some factories and in concern for the community that we find some confluence of the interests of the alkali and factory inspectorates. The chief inspector of factories, several times in his introduction, shows that he has to consider the implications of his thoughts and actions on the community as well as on the factory. Reading the report of the alkali inspector, particularly the sections on the chemical and allied industries and the metal industries, one is aware of the alkali inspectorate's concern to protect the community against many of the noxious and harmful substances which industry expels when protecting its workers by exhaust ventilation.

Community concern leads to community action. The alkali inspector has some interesting comment on this. We may not agree with all he says, but everyone who thinks about these matters should read his report. 'I have said frequently that pressures from an informed public help to gain speedier improvements, raise standards and introduce beneficial legislation, but the problem of communication is important and one that is being tackled. Unfortunately, there are extremists in the environmental movement who believe in the use of scare tactics based on unbalanced information in order to sway public opinion. . . . So far, some, though not all, of the mass information media have preferred to feature the extremists' misrepresentations. . . . A typical example was the recent occasion when great publicity was given to drums of allegedly highly toxic materials being washed ashore in the South West from accidents at sea, di-isocyanates supposedly being amongst them. The scare was tremendous, but in fact investigators found not one single drum of highly toxic material amongst those found on the beaches.'

The alkali inspector's views will be shared by those who regret the apparently increasing tendency of television to treat occupational health and safety as matters for entertainment by controversy rather than as subjects for serious debate. This is a matter 
of concern to all. Increasingly, one hears the pejorative use of 'tele-don' and 'instant expert'.

A special case of the need to consider the community along with the occupational group occurs in agriculture. Of the $\mathbf{1 1 8}$ fatal accidents in agriculture, 23 happened to children under 15 . Drowning in liquid' is the largest single hazard to children on farms. The one fatality from pesticides was a child. Agriculture is, perhaps, our one remaining cottage industry in the sense that the worker's family shares with him the work environment. It will be interesting to see how an inspectorate organized to cope with the factory system deals with this.

\section{Statistics}

Why are statistics of accidents and industrial disease published? The Robens Committee views them simply as byproducts of the information system rather than as primarily providing, at the national level, numerical measures of performance or indices of safety. This is a harsh stricture and would have been generally true a few years ago, although for some years the chief inspector of mines and quarries has both provided a denominator, thus indicating rates per 100000 manshifts, and used 'seriously injured' as an additional index. Both of these useful concepts have come into the reports of the chief inspector of factories in recent years. The setting up of the Accident Studies Unit in the factory inspectorate has increased the value of their statistics out of recognition. The Robens Committee criticized official statistics as being unreliable, due to under reporting, and susceptible to social influences. It is interesting to see how the chief inspector of factories, Mr. Harvey, has anticipated this criticism and dealt with it. A $5 \%$ random sample of notified accidents is thoroughly investigated and allocated to three groups. This is no small task as in 1971 it meant 12999 cases were so treated. Group 1 accidents, rather less than one-fifth of all accidents, are both severe and unambiguously the direct and undoubted result of an accident at work. A study in manufacturing industry showed that the level of reporting of group 1 injuries was much higher than for other injuries and that this group is less susceptible to social influences.

This approach allows the chief inspector to construct a table showing the group 1 rates per 100000 persons employed together with rates (in parentheses) adjusted to changes in average hours worked:

\begin{tabular}{l|c|c|c}
\hline & 1969 & 1970 & 1971 \\
\hline $\begin{array}{l}\text { Manufacturing industry } \\
\text { Construction .. }\end{array}$ & 710 & $670(680)$ & $590(610)$ \\
& 920 & $810(820)$ & $750(770)$ \\
\hline
\end{tabular}

The report on the Office, Shops and Railway Premises Act develops a similar approach to compare the relative chances of fatalities per two million (a curious denominator) at work in different sectors:

\begin{tabular}{|c|c|c|c|c|}
\hline & All & $\begin{array}{c}\text { OSRP premises } \\
\text { wholesale and } \\
\text { warehouses }\end{array}$ & Factories $^{2}$ & $\begin{array}{c}\text { Construction } \\
\text { sites }^{2}\end{array}$ \\
\hline $\begin{array}{l}\text { Falls } \ldots \\
\text { All types }\end{array}$ & $\begin{array}{l}3 \\
7\end{array}$ & $\begin{array}{r}6 \\
41\end{array}$ & $\begin{array}{l}19 \\
86\end{array}$ & $\begin{array}{l}198 \\
403\end{array}$ \\
\hline
\end{tabular}

1'Averaged over 1967-71.

${ }^{2}$ Relates to 1971.

The figures for Mines and Quarries are not strictly comparable as the rates are related to 100000 manshifts worked.

\section{Occupational medicine}

What of medicine in all this? Of course, only the factory inspectorate worked closely with medical colleagues. The mines and quarries and the alkali inspectors have to deal with medical problems but it is clear that the influence of medicine is more remote. The Offices, Shops and Railway Premises inspectorate appear to have no strictly medical problems.

Students of industrial medicine, and examiners too, will feel a touch of nostalgia to learn that the government wool disinfecting station has closed down. The chapter by the chief medical adviser, as he was then, is a 'must' with its reports on Long Term Surveys, the Medical Laboratory, and the ever useful section on Notifiable Industrial Diseases. Not everyone would agree that 'the concentration of lead in the blood is generally regarded as a most important index for the control of the lead hazard in industry', but in general this section of his report serves as a useful up-dating of our practical knowledge of the clinical, and these days biochemical, effects of toxic hazards in industry.

The mines and quarries inspector is less fortunate. Tar and bitumen are used extensively in the quarrying industry. He is left to speculate on the effects of these and to hand out leaflets from the Department of Employment. He has no figures to show the effectiveness of these measures, but he is not led to debate the usefulness or otherwise of routine medical examinations in this situation. Airborne dust in quarries was measured but there seems to have been no parallel medical investigation of the effects of the dust in the concentrations measured. Perhaps the implementation of the Robens Report will give the Employment Medical Advisory Service (EMAS) an opportunity to help in these circumstances. Another example occurs in agriculture. The chief safety officer of the Ministry of Agriculture issues 
certificates of exemption, allowing workers to dispense with certain items of prescribed protective clothing when using an air-conditioned cab or highclearance machine. There is no suggestion that this arrangement is unsatisfactory, but it will be interesting to know of medical evidence to support these moves.

Airborne dust in mines is in a different category. The inspector takes as his biological monitor the number of new cases of pneumoconiosis diagnosed by the medical panels (sic) of the Department of Health and Social Security. Over the last 10 years the results have been:

\begin{tabular}{l|rrrrr}
\hline & 1962 & 1968 & 1969 & 1970 & 1971 \\
\hline $\begin{array}{l}\text { Number of new cases } \\
\begin{array}{l}\text { Incidence per 1 000 } \\
\text { men employed }\end{array}\end{array}$ & 2171 & 775 & 624 & 773 & 623 \\
\hline
\end{tabular}

Thus, although the number of new cases has fallen substantially, the incidence has changed little over the past 10 years. Furthermore, from results of the National Coal Board's five-year $x$-ray scheme, the average 'progression index' rose from 6.6 for 1965 to 8.8 for 1970 .

Finally, we have heard much over the last few years about group medical services for small and medium-sized factories and the need for such services. The chief inspector of factories has some unequivocal comments to make about the 130000 factories which together employ only about $7 \%$ of the total population: 'Some of the most difficult problems do, of course, arise in small factories. Small factories also tend to lack the amenities of larger concerns. But the major problems nevertheless tend to occur in the larger premises.' His figures for accident incidence rates per 1000 employed (Table 20) reveal no startling state of affairs in the little factories:

\begin{tabular}{|c|c|c|c|c|}
\hline \multirow{2}{*}{ Group size } & \multicolumn{4}{|c|}{ Incidence rates per 1000 employed } \\
\hline & \multicolumn{2}{|c|}{$\begin{array}{c}\text { All accidents } \\
\text { Notified Notifiable }\end{array}$} & \multicolumn{2}{|c|}{$\begin{array}{c}\text { Group } 1 \text { injuries } \\
\text { Notified Notifiable }\end{array}$} \\
\hline $\begin{array}{c}1-50 \\
51-100 \\
101-250 \\
251-500 \\
501-1000 \\
1001-5000 \\
5001+\end{array}$ & $\begin{array}{l}25 \cdot 0 \\
33 \cdot 7 \\
35 \cdot 5 \\
37 \cdot 6 \\
38 \cdot 5 \\
33 \cdot 6 \\
27 \cdot 2\end{array}$ & $\begin{array}{l}42 \cdot 6 \\
56 \cdot 3 \\
51 \cdot 1 \\
45 \cdot 4 \\
46 \cdot 7 \\
39 \cdot 3 \\
31 \cdot 6\end{array}$ & $\begin{array}{l}6 \cdot 0 \\
7 \cdot 0 \\
7 \cdot 2 \\
6 \cdot 5 \\
6 \cdot 0 \\
4 \cdot 4 \\
4 \cdot 3\end{array}$ & $\begin{array}{l}7 \cdot 8 \\
8 \cdot 8 \\
8 \cdot 0 \\
6 \cdot 9 \\
6 \cdot 4 \\
4 \cdot 8 \\
4 \cdot 4\end{array}$ \\
\hline Total & $32 \cdot 7$ & $46 \cdot 8$ & 5.9 & $6 \cdot 8$ \\
\hline
\end{tabular}

\section{Reflections}

These are times of great change in occupational medicine as in everything else. What reflections is one left with after reading these reports? Obviously the move toward amalgamation of departments can only be welcomed. It seems odd that industrial accidents and diseases are reported by the employer, and in some circumstances by a doctor, to one government department while the employee reports them to another. Sometimes the departments check with one another to see if there is under-reporting, sometimes the employee's reports (claims) are the only basis the inspector has to go on, as in agriculture. In Mines and Quarries it is even more odd as accidents are reported by the employer and employee (claims) but occupational disease only by the employee (claims). This divorce between compensation and prevention has not happened in France or Germany. Will it continue here?

I have already mentioned the opportunities for the EMAS to assist the mines and quarries inspectorate and perhaps the agriculture inspectorate. It seems curious that in factories a new government medical service will monitor the effectiveness of protective measures against disease but that in mining the inspectorate still depends on employees' claims and on the activities of an industry-based medical service. The future holds a number of intriguing possibilities.

\section{References}

Department of Employment (1972). H.M. Chief Inspector of Factories Annual Report. Cmnd 5098.

Department of Trade and Industry (1972).: Annual Report of H.M. Chief Inspector of Mines and Quarries for 1971 .

Secretary of State for Employment (1972). Annual Report on the Offices, Shops and Railway Premises Act for 1971.

Department of the Environment (1972). 108th Annual Report on Alkali, \&c. Works, 1971.

Ministry of Agriculture, Fisheries and Food (1973) Annual Report on Safety, Health, Welfare and Wages in Agriculture for 1971 .

Safety and Health at Work (1972). Volume 1. Report of the Committee 1970-72. Chairman, Lord Robens. Cmnd 5034.

(All these reports are published by Her Majesty's Stationery Office, London.)

Received for publication 9 March, 1973.

Accepted for publication 11 March, 1973 